\title{
2015 Award for an Exemplary Program or Achievement in a Mathematics Department
}

The DePartment of Mathematics at IOWA STATE UNIVERSITY is the recipient of the 2015 Award for an Exemplary Program or Achievement in a Mathematics Department.

\section{Citation}

The American Mathematical Society is pleased to recognize the Department of Mathematics at Iowa State University with the 2015 Award for Exemplary Program or Achievement in a Mathematics Department. The diversity efforts at all levels of the Department of Mathematics at Iowa State University have been truly exemplary.

This is a department that has managed to do it all. Starting with a highly diverse REU [Research Experiences for Undergraduates] program (25 percent minority students and 40 percent women), they have helped increase the number of underrepresented students going to graduate school in the mathematical sciences. They also managed to diversify their graduate program. Currently 15 percent of their graduate students are minorities and 34 percent of their students are women. Recently one of their former minority students was awarded a highly prestigious NSF [National Science Foundation] funded postdoctoral fellowship from the Alliance for Building Faculty Diversity in the Mathematical Sciences. The Department of Mathematics at Iowa State University is also one of the key members in the Alliance for Building Faculty Diversity in the Mathematical Sciences. Three of the fourteen postdoctoral fellows in this program have gone to Iowa State University for their postdoctoral fellowship. They have also hired one of the alliance postdoctoral fellows to become a tenure track faculty at Iowa State University. All these accomplishments are even more noteworthy due to the fact that Iowa State University is located in a region in the US where there is only a very small minority population.

The department has put many structures into place to ensure that their diversity efforts will be permanent changes. They are one of the few departments in the nation that have a Diversity Director. They also founded the Mathematicians of Color Alliance (MOCA), which is a vertically integrated

DOI: http://dx.doi.org/10.1090/noti1251 mentoring group primarily for graduate students, but also welcoming undergraduates. MOCA has not only helped minority undergraduates get into graduate school but also supports current Iowa State minority graduate students to be successful in their graduate studies.

For the many ways in which the Department of Mathematics at Iowa State University has had a large impact on underrepresented groups in the mathematical sciences, we are happy to present the AMS Award for Exemplary Program or Achievement in a Mathematics Department to the Department of Mathematics at Iowa State University.

\section{About the Award}

The Award for an Exemplary Program or Achievement in a Mathematics Department was established by the AMS Council in 2004 and was given for the first time in 2006. The purpose is to recognize a department that has distinguished itself by undertaking an unusual or particularly effective program of value to the mathematics community, internally or in relation to the rest of society. Departments of mathematical sciences in North America that offer at least a bachelor's degree in mathematical sciences are eligible. Through the generous support of an anonymous donor, the award carries a cash prize of US $\$ 5,000$.

The award is presented by the AMS Council acting on the recommendation of a selection committee. For the 2015 award, the members of the selection committee were: Michael Dorff, Eric Grinberg, Aloysius Helminck (chair), Monica Jackson, and Cesar Silva.

The previous recipients of the award are Harvey Mudd College (2006), the University of California, Los Angeles (2007), the University of Iowa (2008), the University of Nebraska, Lincoln (2009), North Carolina State University (2010), the Math Center at the University of Arizona (2011), Bryn Mawr College (2012), the University of Texas at Arlington (2013), and Williams College (2014). 